\title{
Relationship between Financial Indicators of a Company and the ERP-System Implementation Costs
}

\author{
Strelnik E.U. \\ Usanova D.S. \\ Ushakova T.V. \\ Kazan Federal University, Institute of Management, Economics and Finance, Kazan, 420008, Russia \\ Email address: jstr06@mail.ru
}

\section{Doi:10.5901/mjss.2014.v5n24p15}

\begin{abstract}
The article investigates the issues of implementation of ERP-systems in large Russian companies. The authors put forward and substantiated the hypothesis about the positive impact of implementation of ERP-systems in the company's growth. For the purposes of this study, 30 large Russian companies that had implemented SAP R/3 or SAP ERP modules have been observed. Obtained result shows, that implementation of the ERP-system or its individual modules makes a positive impact in the company's growth, measured by the total assets indicator.
\end{abstract}

Keywords: enterprise resource planning systems, financial indicators, ERP-system, SAP, total cost of implementation, regression analysis, Russia

\section{Introduction}

Corporate governance standards require automation of the entire process of management of a company, which involves combining various administrative, accounting, technical, and other information in a single database. ERP-system provides a unification of control functions for companies and a flexible instrument for real time monitoring of business processes.

Enterprise resource planning (ERP) is a business management software - usually a suite of integrated applications - that a company can use to collect, store, manage and interpret data from many business activities, including: product planning, cost and development manufacturing, marketing and sales, inventory management, payment, human resource management, etc. expected.

In emerging markets is an active implementation of traditional ERP products, and the further growth could be

In order to be more efficient, many companies rely on extensive use of IT, often by installing enterprise resource planning (ERP) systems [1]. The results of Liane Elbertsen, Rik Van Reekum empirical study show that ERP adoption by MEs is most significantly explained by competitive pressure and the compatibility of the software configuration with the firm's business processes [2]. Thus, the implementation of ERP-systems becomes one of the key success factors of company's performance.

The research was conducted in Russia. In this paper we considered large Russian companies, which use SAP ERP software products.

\section{ERP Vendors}

According to Panorama Consulting independent research [3], market leaders are the SAP AG, Oracle Corp. and Microsoft Corp. The share of other companies in the market of corporate information systems is less than $50 \%$ in aggregate. SAP AG is a leader among major international corporations. In Russia Oracle Corp. is the leader in the development of databases, Microsoft Corp. takes a preferential position in software products for small and medium-size enterprises (SMEs), and 1C Company is leader among small enterprises.

SAP AG, Oracle, Microsoft's and 1C's products strengths and weaknesses comparing is summarized in the Table 1. 
Table 1: Comparison of SAP, Oracle, Microsoft's and 1C's ERP software products

\begin{tabular}{|l|c|c|c|c|}
\hline Comparison parameters & SAP & Oracle & Microsoft & $1 \mathrm{C}$ \\
\hline Market share & The leader & Second & Third & Fourth \\
\hline Implementation costs & Highest costs & Medium costs & Lowest costs & Lowest costs \\
\hline Deviation of the actual budget from the planned & The smallest & Medium & The biggest & The smallest \\
\hline Implementation period & Medium & The smallest & The biggest & The smallest \\
\hline Payback period & Medium & The longest & The smallest & Medium \\
\hline Customer satisfaction & Good & Excellent & Good & Good \\
\hline
\end{tabular}

SAP software can be installed in large (multinational) corporations and in SMEs, while Microsoft's and 1C's ERP software mainly implemented in SMEs. The major competitive weakness of SAP ERP software is a very high implementation costs - this factor had a significant influence on the formation of a sample for this study.

\section{Implementation of ERP}

An indispensable part of total cost of ERP implementation (TCI) is software licenses. TCI could be three to five times the purchase price of the software [5]. The actual implementation cost of the Enterprise Resource Planning (ERP) was found to be approximately double the initial SAP costs. The real costs involve time for, among other things, process reengineering, strategic decision making, software add-ons, staff-training, project-management and software maintenance [6].

Analysis of variance, made by Bjorn Johansson, Frantisek Sudzina, Mike Newman, [7] shows actual percentages of ERP systems $\mathrm{TCl}$ (table 2).

Table 2: ERP System TCI Structure (in \%)

\begin{tabular}{|c|c|c|}
\hline & & Average \\
\hline \multirow{3}{*}{ Software license } & Small & $43,15 \%$ \\
\cline { 2 - 3 } & Medium & $45,00 \%$ \\
\cline { 2 - 3 } & Large & $33,42 \%$ \\
\hline \multicolumn{2}{|c|}{ Programming of changes } & $20,85 \%$ \\
\hline \multicolumn{2}{|c|}{ Organizational implementation } & $18,54 \%$ \\
\hline \multirow{2}{*}{ Hardware costs } & With ClO (chief information officer or alike director for IT represented at the & $25,65 \%$ \\
\cline { 2 - 3 } & board level) & $18,31 \%$ \\
\hline
\end{tabular}

Studies on the ERP system TCI structure for the Russia were not conducted. In this study we assume, that TCI of SAP ERP software for Russian companies four times higher than software license costs. TCI is, for purpose of this paper, split into the following two parts: Software Licenses and Other costs, including project management, technical implementation costs and miscellaneous costs.

So, implementation of ERP is costly undertaking, thus all companies are interested in the successful and rapid implementation of the system. According to Irma Becerra-Fernandez, Kenneth E. Murphy, Joyce Elam results [7] just six factors led to successful SAP's R/3 implementation: top management commitment (1); strong project management (2); team member skills (3); team member motivation and dedication (4); effective communication with users (5); an effectively planned and implemented change management strategy (6).

The issues for successful implementation of ERP after extracting from Pareto (80-20 rule) analysis can be listed as follows [10]: education \& training (1), support from top management (2), Properly defined goals \& objective (3), project team competence (4), project management (5), change management (6), proper selection of package (7) and effective communication (8).

Ali Azadeh, Masoud Afshari-Mofrad, Masoud Khalojini study results [11] proved that at 95\% confidence level, infrastructure variable plays a moderating role in the relationship between critical success factors and ERP performance. Also, results show that organisational infrastructure has the most important effect on ERP performance and 'strategic goals' is the most important critical success factor.

High total cost of implementation (TCl) of ERP makes the decision-making process of its adoption complex. Profitability has the most significant impact on the incremental investments of Russian companies [12]. For the purposes 
of this study, we sampled large public Russian companies that have enough financial, technical, human and other recourse to implement SAP ERP successfully.

\section{Data and Methodology}

In our study we observed 30 large Russian companies that had implemented SAP R/3 or SAP ERP modules. Sampling includes the petrochemical industry, communications industry, metallurgy, vehicle production, energy, banks, transport, and retailing (Fig. 1).

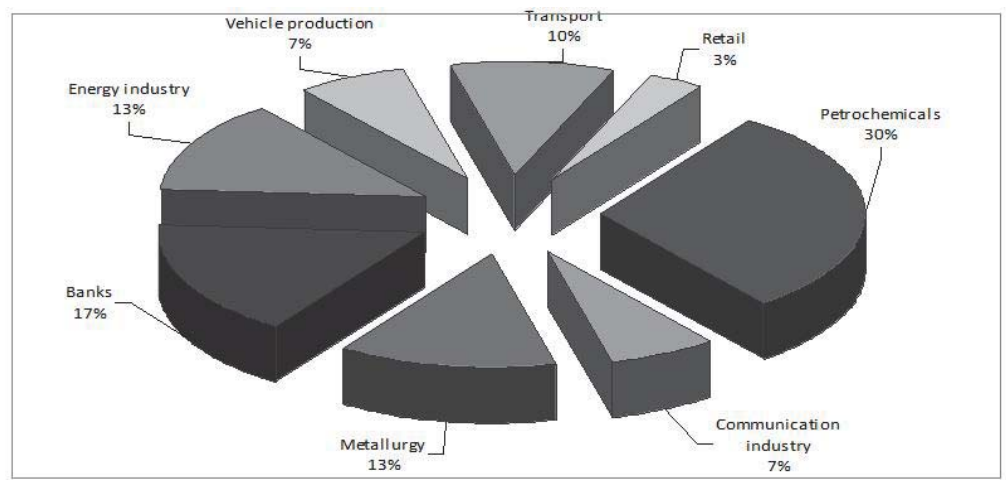

Figure 1. Companies sampling

Hypothesis: investments in SAP ERP (SAP/3) are positively correlated with the size of a company. The growth of company is explained, among other factors, by investments in SAP ERP (SAP/3).

For our research we have selected the following financial indicators that could be calculated using financial statements: total assets (TA), liabilities to equity ratio (L/E), EBIT, interest expenses, ROA, ROS, ROE. The SAP ERP (SAP/3) implementation costs were counted by ERP ROI Calculator (Panorama Consulting method).

In this study we used the regression analysis method. On the first stage we have got a correlation matrix to identify the relationship between the indicators (Pearson criterion). It allowed excluding from the model irrelevant factors and cross-correlated indicators. On the second stage we have received several regression models in which each of the financial indicators had been nominated as the dependent variable. We have chosen one regression model based on coefficient of determination and Fisher's exact test. Then we excluded insignificant variables based on T-Statistics criteria from the model.

\section{Results}

The regression analysis results are summarized in the Table 3.

Table 3: Regression analysis results

\begin{tabular}{|c|c|c|}
\hline & coefficients & t- statistics \\
\hline Y-crossing & 6,4898 & 6,12 \\
\hline Average TCI (Ln) & 0,1528 & 1,80 \\
\hline ROE & $-1,1081$ & $-2,59$ \\
\hline Interest expense (Ln) & 0,3365 & 4,29 \\
\hline Ebit (Ln) & 0,3009 & 5,48 \\
\hline Critical t-statistics & & 1,7 \\
\hline
\end{tabular}

Dependent variable is total assets (TA).

Independent variables are liabilities to equity ratio (L/E), EBIT, interest expenses, ROA, ROS, ROE, TClaverage.

After excluding the insignificant variables, we have got the following equation (Formula 1), determination coefficient

$\left(R^{2}\right)$ is 0,84 :

$y=6,49+0,15 x_{1}-1,11 x_{2}+0,34 x_{3}+0,3 x_{7},(1)$ 
where: $y$ - total assets (TA), $x_{1}$ - average TCl (natural logarithm); $x_{2}$ - ROE (coefficient); $x_{3}$ - interest expenses (natural logarithm); $x_{4}$ - EBIT (natural logarithm).

Figure 2 illustrates fluctuation of the total assets (TA) and the total cost of implementation (TClaverage).

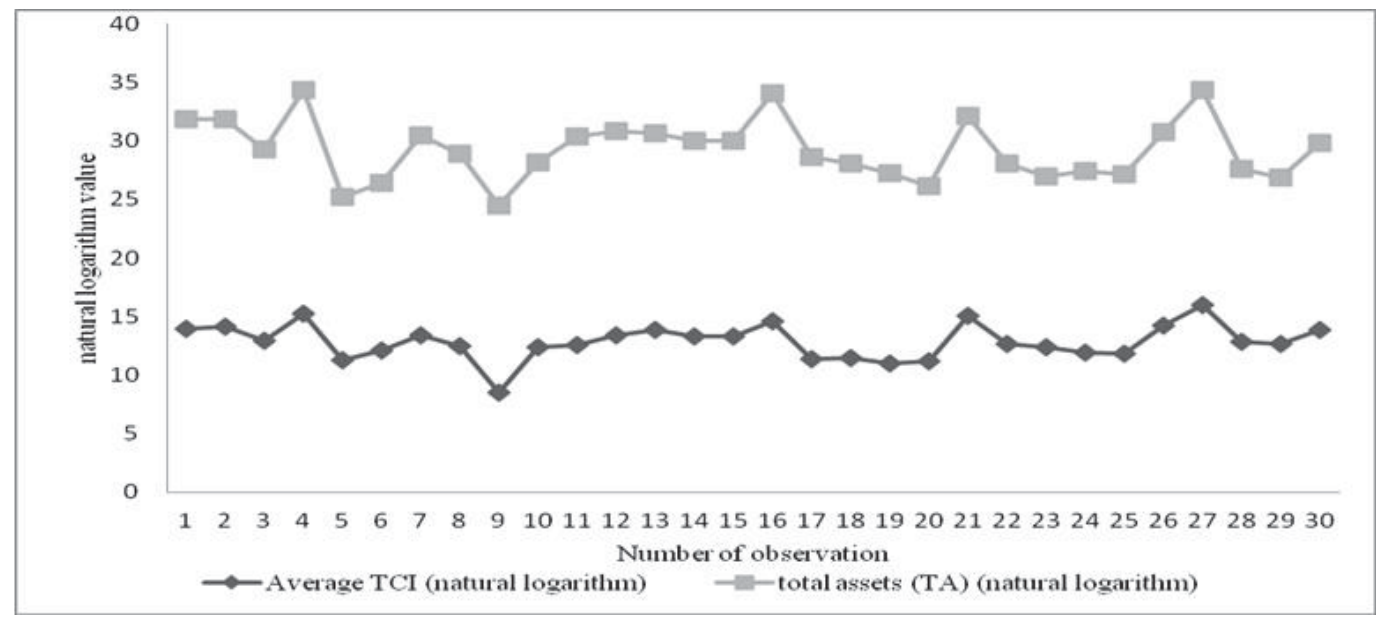

Figure 2. Fluctuation of the total assets and the total cost of implementation

Figure 2 shows, that the size of a company (the total assets) is correlated with the investment activity (total cost of implementation of SAP ERP, SAP R/3), the correlation coefficient is 0,58 .

\section{Conclusion}

Enterprises recently tend to implement their new enterprise information systems like the Enterprise Resource Planning (ERP) system in order to gain their competitive advantages and bring up their business efficiency, but the efficiency gained from this new implementation is not quite clear and is difficult to be identified [11].

The empirical results, obtained by Huang Shaio-Yan, Lin Ching-Wen, Wong Seng-Lee, Tsai Ming-Chun, show that ERP implementation can positively affect the process capital of Intellectual Capital (IC); process capital can positively affect customer capital and customer capital ultimately affects business performance. Companies implementing ERP can build process capital to meet the challenges of the competitive market environment [12].

The results of this study show that investments in SAP ERP (SAP/3) are positively correlated with the size of a company. This conclusion is confirmed by the regression and correlation analysis. The growth of company is explained, among other factors, by investments in SAP ERP (SAP/3), because we obtained positive relationship between the total costs of implementation of SAP ERP, SAP R/3 and the total assets of a company, where total assets indicator was calculated with the time lag. The time lag was determined on the base of payback period.

In our feather studies we propose to increase the size of the sample and thus to observe not only large companies, that have an advantage in terms of economic competitiveness due to their size and the financial benefits they enjoy on the global market [13], but also Small and Medium Enterprises (SMEs).

\section{References}

Olsen, K. O., and Saetre, P. (2007). IT for Niche Companies: Is an ERP System the Solution? Information System Journal, 17, 1, pp. 37 58.

Liane Elbertsen, Rik Van Reekum (2008). To ERP or not to ERP? Factors influencing the adoption decision. International Journal of Management and Enterprise Development, Vol. 5, No.3 pp. 310 - 330.

Guide to ERP Systems and Vendors (2011). An Independent Research Report. Panorama.

Bagautdinova N.G., Khadiullina G.N.,. Shevko N.R, Pratchenko O.V. Condition and Development Characteristics of The Russian Market of Information Technilogies// Mediterranean Journal of Social Sciences.- Vol.5, No12, (2014)-pp.21-26.

Bingi, P., Sharma, M. K., and Godla, J. K. (1999). Critical Issues Affecting an ERP Implementation. Information Systems Management, 16,3, pp. 7-14.

Marie Griffiths, Aleksej Heinze, Anthony Ofoegbu (2013). The real SAP® Business One cost: a case study of ERP adoption in an SME. 
International Journal of Management Practice, Vol. 6, No.2 pp. 199 - 215.

Bjorn Johansson, Frantisek Sudzina, Mike Newman (2011). ERP system implementation costs and selection factors of an implementation approach. International Journal of Business Information Systems (IJBIS) 6(1), pp.87-105

Irma Becerra-Fernandez, Kenneth E. Murphy, Joyce Elam (2005). Successfully implementing ERP: the IBM personal systems group experience. International Journal of Internet and Enterprise Management, Vol. 3, No.1 pp. 78 - 97.

Safiullin N.Z., Gafurov I.R., Safiullin L.N., Odintsova U.L. Modern Information Resources in Education// Mediterranean Journal of Social Sciences.- Vol.5, No12, (2014)-pp.113-116.

Annamalai C., Ramayah T. (2011). A review of ERP implementation in India. International Journal of Business and Systems Research, Vol. 5, No.4 pp. 406 - 421.

Ali Azadeh, Masoud Afshari-Mofrad, Masoud Khalojini (2012). The role of organisational infrastructure in successful ERP implementation: an empirical study by hierarchical regression and PCA. International Journal of Business Information Systems, Vol. 10, No.1 pp. 40 - 67.

Safiullin L.N., Kramin M.V., Kramin T.V., Timiryasova A.V. Drivers of economic growth and investment attractiveness of Russian regions. Life Science Journal 2014; 11(6s): $526-530$.

Safiullin, M.R., Ankudinov, A.B., Lebedev O.V. (2013). Research into the motives and factors of investment activities of enterprises. Studies on Russian Economic Development, 24 (4), pp. 385-393.

Ruey Kei Chiu, S.C. Lenny Koh, Angappa Gunasekaran (2006). An empirical analysis of business efficiency from the implementation of enterprise information system. International Journal of Business Information Systems, Vol. 1, No.4 pp. 387 - 407.

Huang Shaio-Yan, Lin Ching-Wen, Wong Seng-Lee, Tsai Ming-Chun (2007). The impact of ERP implementation on business performance - an integrated investigation model. International Journal of Manufacturing Technology and Management, Vol. 12, No.4 pp.342 - 359 .

Zoltan Szegedi (2008). Logistics in small and medium companies in Central and Eastern Europe. International Journal of Procurement Management, Vol. 1, No.3 pp.359 - 370. 